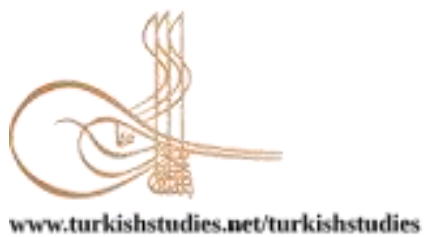

Turkish Studies

Research Article / Araştırma Makalesi

\title{
Özgün Baskıda Deneysel Yaklaşımlar: Karen Kunc
}

Expertimental Approaches in Printmaking: Karen Kunc

\author{
Tuba Kınay Gör*
}

\begin{abstract}
Over time, there have been new searches and techniques in the art of print painting, which dates back to cave paintings. Especially with Atelier 17, artists were encouraged to do experimental printing. There are many artists today who do experimental print. Karen Kunc, one of these artists, has also produced many works based on experimentation in original printing. The artist, who mostly makes wood prints (engraving) by way of 'reduction', decides on the colors at the printing stage while drawing his sketches. She prepares her works for printing by preparing "negative" and "positive" patterns for each color. In the printing phase, she usually uses paper templates to pass the color through the openings on the mold. The artist's performance depends on the mood at the time of printing. Since she does not want to decide on the color in advance, she makes random choices according to the course of the picture and moves step by step towards the resolution of the picture. She not only printed prints that could hang, but also accordion-shaped booklets. In this study, the role of Karen Kunc's psychology in the production of art was emphasized and descriptive analyzes were made about some of her selected works. In these analyzes; It is seen how the artist transfers the world of images to his works with the technique of print painting through experimentation. Pushing the boundaries of a primitive material such as wood, the artist inspired by viewing and contemplating the forces of the natural world, uses images such as mountains, stones, water, trees and roads in his works. Energy and enthusiasm are at the forefront in their prints. Kunc is a successful artist who, with her experimental approach, shows the audience what can be done by pushing the boundaries in original print.
\end{abstract}

Structured Abstract: Creative approaches in the art of printmaking first manifested themselves in the workshop (Atelier 17) established by Stanley William Hayter in Paris in the early 1930s. Hayter is an artist who advocates learning through experience and action, allowing the "possibility of exploration" with enthusiasm for the environment where "manipulation, obstruction and commands are avoided" between masters and new generations. Over the years, thousands of independent artists have spread this creative attitude by passing through this workshop or being influenced by it. This enabled experimental approaches to gain a unique identity in printmaking. With the establishment of one of the first university printing studios, Mauricio Lasansky, at Lowa University in the USA in 1943, 19th century concepts of printing were virtually 'destroyed'. In fact, Lasansky's contribution is the reinvention of the process and the oppression in a sense; In this way, printing with different plates was started using many techniques (Kunc, 2001). It can be said that Karen Kunc, one of the artists of today, started this experimental print with the effect.

\footnotetext{
* Dr. Öğr. Üyesi, Sinop Üniversitesi, Güzel Sanatlar Fakültesi, Resim Bölümü Asst. Prof. Dr., Sinop University, Fine Arts Faculty, Department of Painting ORCID 0000-0001-8818-3152

tkinaygor@sinop.edu.tr

Cite as/ Atıf: Kınay Gör, T. (2021). Özgün baskıda deneysel yaklaşımlar: Karen Kunc. Turkish Studies, 16(1), 237-

251. https://dx.doi.org/10.7827/TurkishStudies.47887

Received/Geliş: 07 December/Aralık 2020

Accepted/Kabul: 20 Şubat/February 2021

Checked by plagiarism software

Published/Yayın: 25 Şubat/February 2021

CC BY-NC 4.0
} 
Kunc's works bear largely traces of Japanese wood prints and the work of German Expressionists. When his works are analyzed as a series, it is seen that he combined European modernism with traditional Japanese printmaking in a sense. By synthesizing the remnants of both early twentieth-century German Expressionism and seventh-century Japanese ukiyo-e prints, it is clear that she created new works with great finesse and complexity, and it appears that she produced many experimental works based on automatism with this trend. Working as an academic at the University of Nebraska, the artist has produced works with many techniques such as engraving, lithography, serigraphy and wood printing. She uses these techniques sometimes alone or mixed together in the same picture. Thus, each of these techniques provides it with a unique line and surface quality that the reductive approach does not provide (Farber, 2007). Karen Kunc made woodprints mostly through 'reduction'. In addition to small size prints, it is also possible to see large size prints up to 200 cm wide.

It is possible to see many traces of nature in her works. Throughout her life, the artist uses images of the visible world, trees, rivers, fences and gutters, etc. She stylized and depicted the irresistible forces such as flood, thunder, gravity and growth, using the original printing technique, with many different codes, signs and symbols. The artist first draws her sketches and then decides which colors to print in the printing phase. It prepares its works for printing by preparing 'negative' and 'positive' molds for each color. In the printing phase, it usually uses paper templates to pass the color through the openings on the mold. The artist's performance depends on the mood at the time of printing. Since she does not want to decide on the color in advance, she makes random choices according to the course of the picture and moves step by step towards the resolution of the picture. The randomness is very important in her work. She is not only printed hang-up prints, but also accordion-shaped booklets. Karen Kunc, who has been awarded many awards, is considered an archaic artist because she produces contemporary works with a simple material such as wood. The artist's special passion was the art of engraving, which she used to reduce colors. Essentially, cutting, inking, printing, and recutting a block until the desired result is achieved in the composition is actually a risky method because there is no return. There is also little chance of editing in a way that exists in more traditional printmaking, where color and image are layered by overlapping different blocks. In the words of Janet L. Farber, this is a process of creation through erosion (Farber, 2007). This is the most important feature that distinguishes her from other print artists.

Apart from the paintings that are framed and hung on the wall, the artist also produces threedimensional sculptural works on the ground. Some of these print pictures are horizontal and some are vertical. However, most of them are made in the form of very wide or narrow panoramas, which are beyond our daily viewing habits. These are actually the only compositions created in the form of a booklet like a threedimensional accordion. With these works, Kunc is an indication of what kind of success she will bring in the original printing with the awareness of experimentation and randomness in terms of technique and presentation.

Her works come from her fascination with natural forces such as weather, migration and erosion. Its unique style of printing includes iconic images such as creating and preserving these concepts and reference to human myth and metaphor. Her prints record the destruction and creation process inherent in woodprinting, and as an artist she takes an all-knowing role as the process towards the resolution of his evolutionary choices and images. Pushing the boundaries of a primitive material such as wood, the artist aims to achieve success through a symbolic expression based on her own life experience. Therefore, images such as mountains, stones, water, trees, and roads become symbols of his thoughts between the sensual and the earthly world. Another remarkable element is the energy and enthusiasm that comes to the fore in her prints. Karen Kunc makes a very significant impact on the audience with this experimental approach, and this proves what can be done by pushing boundaries in the original edition. The layers that the artist applies in his print paintings, by giving the audience the opportunity to examine expressionism and innovative printing techniques, show what is possible with experimentation in printmaking.

Although she is recognized as one of the most prolific and influential artists of contemporary print art in the world, her name is rarely mentioned in local sources. For this reason, this study has been prepared using article and exhibition catalogs, mostly based on translation from foreign sources. In this study, the role of Karen Kunc's psychology in the production of art was emphasized and descriptive analyzes were made about some of her selected works. In these analyzes; How the artist transfers the world of images to her works with the technique of printmaking through experimentation. The emphasis is on how a primitive material such as a tree pushes its boundaries, how it depicts the forces of the natural world with images such as mountains, stones, 
water, trees and roads, inspired by viewing and contemplation. She is emphasized that energy and enthusiasm are at the forefront in her prints.

Keywords: Printmaking, Karen Kunc, experimentality, randomness, woodcut.

Öz: Geçmişi mağara resimlerine kadar uzanan baskı resim sanatında zaman içerisinde yeni arayışlar ve teknikler olmuştur. Özellikle Atölye 17 ile birlikte sanatçılar deneysel baskı yapabilme konusunda cesaretlenmiştir. Günümüzde deneysel baskı yapan pek çok sanatçı vardır. Bu sanatçılarından Karen Kunc da, özgün baskıda deneyselliğe dayalı pek çok eser vermiştir. Çoğunlukla 'eksiltme' yoluyla ağaç baskılar (gravür) yapan sanatçı, eskizlerini karakalem yaparken, renklere basım aşamasında karar vermektedir. Her renk için 'negatif' ve 'pozitif' kalıplar hazırlayarak çalışmalarını baskıya hazırlar. Basım aşamasında genellikle kalıp üzerindeki açıklıklardan rengi geçirmek amacıyla kağıt şablonlar kullanır. Sanatçının performansı, baskı anındaki ruh haline bağlıdır. Renge önceden karar vermek istemediği için gidişata göre rastlantısal seçimler yaparak, resmin çözümüne doğru adım adım yol alır. Yalnızca asılabilen baskıresimler değil aynı zamanda akordeon şeklinde kitapçıklar da basmıştır. Bu çalışmada, Karen Kunc'un psikolojisinin sanat üretimindeki rolü üzerinde durulmuş ve seçilen bazı eserleri hakkında betimsel analizler yapılmıştır. Bu analizlerde; sanatçının imgeler dünyasını deneysellik yoluyla baskı resim tekniğiyle eserlerine nasıl aktardığı görülür. Ağaç gibi ilkel bir malzemenin sınırlarını zorlayan sanatçı, doğal dünyanın güçlerini seyir ve tefekkürden ilham alarak, eserlerinde dağ, taş, su, ağaç ve yol gibi imgeler kullanır. Baskılarında enerji ve coşku ön plandadır. Kunc, deneysel yaklaşımlarıyla izleyiciye özgün baskıda sınırların zorlanarak neler yapılabileceğini gösteren başarılı bir sanatçıdır.

Anahtar Kelimeler: Baskı resim sanatı, Karen Kunc, deneysellik, rastlantısallık, ağaç baskı.

\section{Giriş}

Baskıresim sanatında yaratıcı yaklaşımlar, ilk kez Stanley William Hayter'in 1930'ların başlarında Paris'te kuruduğu atölyede (Atelier 17) kendini göstermiştir. Hayter, deneyim ve eylem yoluyla öğrenmeyi savunan, ustalar ve yeni nesiller arasında "yönlendirmelerin, engellemelerin ve komutların kaçınıldı̆̆g”" ortama duyulan coşkuyla 'keşif olasıllı̆ıına' izin veren bir sanatçıydı. Yııllar içinde binlerce bağımsız sanatçı bu atölyeden geçerek ya da ondan etkilenerek bu yaratıcı tavrın yayılmasına hizmet etti. Böylelikle baskıresim deneysel yaklaşımlarla özgün bir kimlik kazanmaya başladı. ABD'deki ilk üniversite baskı atölyelerinden biri olan Mauricio Lasansky'nin 1943'te Lowa Üniversitesi'nde kurulmasıyla da, 19. yüzyıl bask1 kavramları fiilen 'yok edildi'. Lasansky'nin miras1, sürecin ve baskının bir anlamda yeniden keşfedilmesidir; onu sayesinde çok sayıda teknik kullanılarak farklı plakalarla baskı yapılmaya başlandı (Kunc, 2001). Günümüz sanatçılarından Karen Kunc da bu deneysel baskının etkisine kapıldı ve bu eğilimle otomatizme dayalı pek çok deneysel eser üretti.

Nebraska Üniversitesi'nde akademisyen olarak görev yapan sanatçı, gravür, litografi, serigrafi ve ağaç baskı gibi pek çok teknikle baskılar yapar. Kunc, bu teknikleri bazen tek başına, bazen de aynı resimde bir arada karışık olarak da kullanmaktadır. Böylelikle bu tekniklerin her biri ona, indirgeyici yaklaşımın sağlamadığı, benzersiz bir çizgi ve yüzey kalitesi sağlar (Farber, 2007). Küçük ebatlı baskıların yanı sıra $200 \mathrm{~cm}$ genişliklere varan büyük boy baskılar da görmek mümkündür.

Kunc'un gravürleri, başlangıçta soyut olarak algılansa da, jeomorfik form ve daha ileri incelemelerde organik elementler öneren farklı organik şekillerden oluşur. Kunc'un yumuşattığ 1 renkli mürekkepler, yumuşak, eterik tonlardan yoğun, canlı tonlara kadar uzanır. Çoğunlukla Japon el yapımı kağıtlara basan sanatçının baskıları sadece göze çarpan canlı renkler ve coşkulu şekiller dizisiyle zevk vermekle kalmaz, aynı zamanda izleyiciyi çeşitli evrimsel ve ekolojik süreçleri de düşünmeye zorlar. Esasen sanatçı, bizi çevremizdeki ‘Dünya' hakkında daha farklı düşünmeye teşvik 
etmekte ve özgün baskı tekniğiyle çok farklı resimler de yapılabileceğini göstermektedir (Mamiya, 1991).

Pek çok ödüle layık görülen Karen Kunc, arkaik bir sanatçı olarak değerlendirilir. Sanatçının özel tutkusu renkleri azaltma şeklinde kullandığı gravür (ahşap plakayı oyma/Ağaç Baskı) sanatı olmuştur. Kompozisyonda istediği sonucu elde edene kadar bir bloğun kesilmesi, mürekkeplenmesi, basılması ve tekrar kesilmesi aslında riskli bir yöntemdir çünkü geri dönüş yok. Ayrıca renk ve görüntünün farklı blokların üst üste binmesiyle katmanlandığı daha geleneksel baskı yapımında var olan bir şekilde düzenleme yapmak için şansı çok daha azdır. Janet L. Farber'ın deyimiyle, bu bir erozyon yoluyla yaratma sürecidir (Farber, 2007).

Sanatçı çerçevelenip duvara asılan resimler dışında üç boyutlu ve zemine ayak basan heykelsi çalışmalar da üretmiş̧ir. Bu baskıresimlerin bazıları yatay, bazıları da dikeydir. Ancak çoğu, günlük izleme alışkanlıklarımızın dışındaki ölçülerde oldukça geniş veya dar panoramalar şeklinde yapılmıştır. Bunlar üç boyutlu akordeon gibi kitap-çık şeklinde oluşturulmuş tek kompozisyonlardır.

\section{Karen Kunc ve Deneysellik}

Karen Kunc çalışmalarına öncelikle eskizler yaparak başlar. Renklendirmeyi, baskı işlemi sürecine bırakmayı tercih ettiği için bu taslakları önce karakalem ile çizer (Grabowski \& Fick, 2011: 88). Sanatçı, genellikle doğal dünyadan esinlendiği temalar üzerine doğaçlama yaparak, dürtü etkisine ve malzemenin gerekliliğine yanıt olarak çalışma ilerledikçe geliştirdiği kompozisyon öğeleriyle başlar. Çalışma şeklini şöyle ifade eder; "Her yere bakarım; gözlerim sürekli, görsel veriler için araş̧ııır- manzaranın içinde, yalın gökyüzüne karşı, ağaç dallarının ilginç grafik örüntülerinde, şeyler arasindaki boşluklarda ya da malzemelerin süprizli ve tuhaf bitişmelerinde. Çevrede insan izlerini ararım - varlı̆̆ın yokluğunu ve zamanın tükenişini. Yolculuk yaparken gördüğümü, kendi ellerimle ifade etmek için, yaşamdan çizimler yapıyorum." (Grabowski, Fick, age). Belki de baskılarının çekiciliği de, bu süreçten ileri gelmektedir.

Sanatçının birincil ortamı gravür olsa da, yöntemleri o alan için tamamen geleneksel değil. Baskıları, alışılmadık derecede az sayıda ahşap plakayla ürettiği için önemli sayıda yoğun renk içeriyor.

$\mathrm{Bu}$ amaca şablonları belirli bir tahta bloğuna yapıştırarak ulaşıyor - bu, aslında serigrafi baskısından ödünç alınan bir yöntem. Bu da sanatsal ve teknik yenilikler bakımından Kunc'u aynı teknikle resim yapan diğer sanatçılardan ayırdı. Kunc'un çalışmaları, baskı resim üzerine çeşitli yayınlarda yer aldı. Baskıları, New York'taki Museum of Modern Art, Washington D.C.'deki Smithsonian ve Londra'daki Victoria-Albert Museum dahil olmak üzere dünya çapında çok sayıda büyük müzenin koleksiyonlarında yer almaktadır (https://kiechelart.com/artist/karen-kunc/).

Kompozisyonel açıdan bakıldı̆̆ında Kunc'un baskıları, yoğun renkler arasındaki form ve karşıtlıkları dengeleyerek uyumu yakalamaktadır. Sert dikdörtgen biçimler ve kıvrımlı çizgiler arasındaki, yoğun renk doygunluğu ve ince geçişler arasındaki bu dengeler, aynı zamanda, doğal dünyada birbirine karşı kurulan kuvvetlerin metaforları olarak veya büyük bir denge için kişisel arayışını yansıtmakta olduğu söylenebilir. Kunc'un baskıları, planını şansa karşı dengeleyen bir sürecin sonucudur; öncelikle kompozisyonunun geniş ana hatlarını yerleştirir, o an için ilgisini çeken motifleri minyatürde keşfeden sayısız küçük eskizlerden yola çıkarak geliştirir. Baskı için blokları kestikçe, zanaatını, görüntüleri üzerinde çalıştığı malzemelere uyarlamak için kullanır. Ahşap kalıbını hazırlarken, ahşabın ona rehberlik etmesine izin de verir (Farber, 1995). Aynı şekilde, baskılarının son renkleri, birçok mürekkep katmanının üstü üste gelmesiyle ortaya çıkar ve bu da sürekli olarak yaptığı deneylerin sonucudur. 


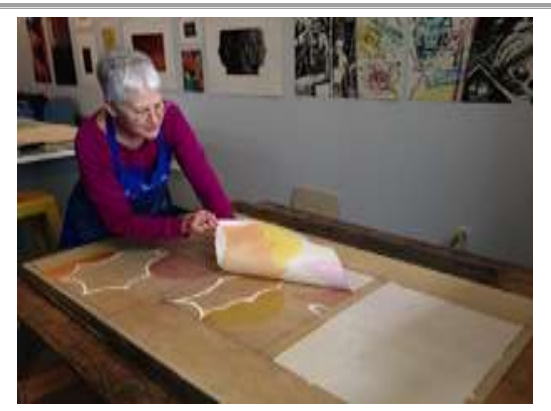

Kunc'un her eserinde doğadan izler kendini gösterir. Sanat hayatı boyunca, gördüğümüz dünyadaki imgeleri ağaçlar, nehirler, çitler ve oluklar vb. stilize etmiş ve sel, gök gürültüsü, yerçekimi ve büyüme gibi karşı konulamayan güçleri pek çok farklı şifre, işaret ve semboller ile özgün bask1 tekniğini kullanarak resmetmiştir. Bunu da şöyle ifade etmektedir: "Dünyay1 şekillendiren güçlerin enerjisini ve hava durumu, göç, erozyon gibi görünmez doğa döngülerini ana içerik etkileri olarak kavramlaştırıyorum. Çalışmam, 'coşkulu' doğa temelli soyutlamalar, lirik ve şiirsel ve grafiksel olarak güçlü olan ahşap blokların üretken oyulmasında enerjiyi yakalıyor" ( https://femmesfollesnebraska.tumblr.com). Baskıresimlerinde de bu enerji ve coşkuyu görmek mümkündür.

Baskıları ister cesur baskı, isterse bastırılmış çağrışımlar olarak betimlensin, Kunc'un aslında doğayla kültürel ilişkimizin bir parçası olan sihri ve manipülasyonu ifade etme arzusu güttüğü görülmüştür. Sanatçının gravürleri her zaman, bu ortamın içsel özellikleri ile nesneyi bir gravür olarak okumanın ötesine, bir baskıya veya daha basit bir şekilde sanat eserine itme isteği arasında amaçlı bir gerilim sergilemiştir (Farber, 1995). Eserlerinde damarı ve dokuyu kullandığı görülür.

Kunc'un eserlerine verdiği isimler, imgelerinin organik kökenine değinir. Söz konusu başlıkların işlevi, bir harita oluşturucunun izleyiciyi yönlendirmek için bir pusula ile uygulayabileceği yöntemle aynıdır. Başlık, bize soyut imgelerinin izini sürmek için bir ipucu sağlar, bazen bir soyutlama için bir yorum önerir, ancak çoğu kez birkaç baskıda paylaşılan bir görsel unsuru pekiştirir. İzleyici, bir kod kıııcı gibi ipuçlarını toplamaya, baskıdan baskıya kadar ipuçlarını biriktirerek nihayetinde dilbilimsel olmayan, ancak hem sözlü hem de görselden oluşan karma bir lehçede bir anlayışa teşvik edilir. Esasen Kunc'un kompozisyonları, ortam ve süre bakımından birbiriyle uyum içinde ve sanatçının çalışmalarına temeldeki gücü veren de budur (Stevens, 2007).

\section{Karen Kunc'un Ağaç Baskıları}

Sanatçının son dönem gerçekleştirdiği ağaç baskıları, Kunc'un öğretmenliğe başladığında uygulattığı gravür tekniğinin ve yeteneklerinin genişletilmiş bir araştırmasının sonucudur. Kunc, Lincoln'da yer alan Nebraska Üniversitesi'nde önce baskı resim eğitimi aldı ve ardından Ohio State Üniversitesi'nde lisans üstü eğitimi sırasında bu ilgisini sürdürdü; ve bu dönemde gravür, serigrafi ve litografi tekniklerine odaklandı. Ağaç Baskı olarak ilk kapsamlı çalışmalarını öğretme aşamasında deneyimledi. Sanatçı gravürün kendisine sağladığı sınırsız olasılıklara hayran kaldı. Yine bu dönemde Kunc, tuval üzerine resimlerde bulunmayan incelik ve illüzyon niteliklerine yönelik baskılar yapmaya da ilgi duydu (Mamiya,1991). 


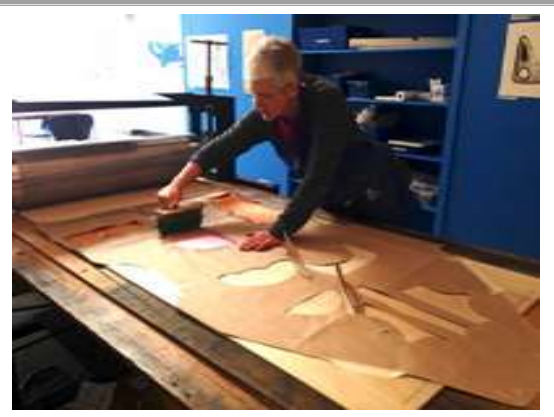

Karen Kunc zaman içerisinde, olağanüstü sonuçlar veren ahşap baskılarını üretmek için bir teknik geliştirdi. Bu tekniğe göre önce, bir ön iskelet hazırlamakta sonra, tasarımı 1/4 inç kalınlığında bir kontrplağa aktarmaktadır. Kunc, her renk için ayrı bir blok üretmek yerine (tek bir baskıda kırk adede kadar olabilir), kağıt şablonlar yardımıyla tüm renkleri basmak için genellikle aynı tahta kalıbı kullanır. Bu şekilde her şablon, yağ bazlı mürekkebin belli bir alana uygulamasına imkan tanır. Hazırladığı ahşap kalıbı pres ile basıldıktan sonra, kă̆ıda yeni basılmış olan alan bloktan kesilir veya zımparalanır ve ardından blok başka bir şablonla mürekkeplenmeye ve diğer renk alanları için basılmaya hazır hale gelir. Bu uzun süreç nedeniyle, yirmi ila yirmi beş adet çoğaltılan bir baskı, genellikle iki ile dört hafta arasında tamamlanmaktadır (Mamiya, 1991). Kunc, çizdiği eskizleri asetata aktardıktan sonra elindeki taslağı tersten iki kalıba da transfer eder ve ağacı belirlemek ve çizimi korumak için yüzeye gomalak cilası uygular. Kapılarını da 'negatif' ve 'pozitif' olacak şekilde birbirine karşıt gelmesini planlayarak oyma işlemini gerçekleştirir. Her bir rengi bastıktan sonra, kalıbı yeniden oyarak 'eksiltme' yöntemiyle devam eder. Çalışma sürecini sanatçı şöyle açıklar: "Çeşitli renklerin bir çırpıda basılmasına, olanak verecek şekilde, seçilmiş bölgelere mürekkep vermek için, kalıp üzerindeki açıklıklardan rengi geçirmek amacıyla genellikle kağıt şablonlar kullanırım. Renk çeşitliliğini ve parlaklığını sağlamak için başlangıçta kağıdın beyazına karşı, çok sayıda renkle bask yapmayı denerim." (Grabowski , Fick, 2009:88). Böylelikle çalışmalarında kullandığı renklerin uyumunu nasıl sağladığı daha iyi anlaşılıyor.

Kunc, bu şekilde çeşitli denemeler yapması, baskı tekniğinin alışılmış yöntemlerinin aksine, bir kavramın evrimsel bir fikirden karmaşık ve ilgi çekici bir imaja dönüşmesine izin vermektedir. Bu durumu kendisi şu sözlerle aktarır: "Bunu bu şekilde yaparak ne olacağını asla bilemiyorum. Bu, baskının çok basit bir fikirden bir daha olmasını bekleyemeyeceğim bir şeye dönüşmesini sağllyor" (Mamiya, 1991).

Sanatçının gelişen görüntüye olan duyarlılığı, bu baskıların plansız olduğunu düşündürüyor gibi görünse de, Kunc, tüm çalışmalarının temel bir yapıya sahip olduğunu vurgular. Zaten her esere farklı şekil ve renklere rağmen tutarlılığını veren de bu örgütsel yapıdır. İzleyenleri, büyüleyici şekiller ve coşkulu renklerle kuşatarak, baskı resim ile etkileşimlerini ilk gözlemlerinin ötesine genişletmeye zorlamaktadır. Her ikinci bakışta, izleyici yeni bir şey kavrar. Sanatçının kullandığı bu teknik ile baskı resimler, önce tuhaf gelmesine rağmen, ikinci kez bakıldığında daha gizemli bir hal almaktadir.

Başlangıçta karmaşa hissi veren bu çalışmalar aslında sanatçının her baskıda ortaya çıkan sayısız görsel etkileşimi düzenleme yeteneğine tanıklık etmektedir. Öncelikle renklerin yoğunluğu ilk etki yaratır ve izleyiciyi baskı resmi daha büyük bir dikkatle incelemeye ikna eder. Ardından, ince varyasyonlar ve benzersiz yan yana gelmeler kendini gösterir. Resmin bazı kısımlarında, kargaşa tonları uyumsuz bir şekilde çatışırken, diğer taraflarda renkler ruhani genişliklere açılır.

$\mathrm{Bu}$ baskılardaki görüntünün karmaşıklığı, alan ve derinliğin çözünürlüğü ile daha da artmaktadır. Karen Kunc, burada işlediği görüntülerin öncelikle iki boyutlu olduğunu iddia eder: "Uzayda işlerin nasıl yürüdügüule ilgilenmiyorum... Daha çok iki boyutlu düz şekillerle ilgileniyorum" demektedir. Ancak, her baskıda üç boyutlu formlar ve uzamsal ilişki önerileri olduğu 
da inkar edilemez bir gerçekliktir. Örneğin, Found / Made Mosaic (1990)'da (Bkz. Resim 1) dikdörtgen elemanlar mimari yapılar olarak adlandırılır. İki boyutlu şekiller ile üç boyutlu formlar ve mekanlar arasındaki belirsizlik, izleyicinin karşılaştığı çeşitli şekillerle abartılmıştır. Her baskıda, keskin bir şekilde çizilmiş kenarlara sahip şekillerin yanı sıra, diğer alanlara kusursuz bir şekilde giren veya havadar hiçliğe dönüşen şekiller görülmektedir (Mamiya, 1991).

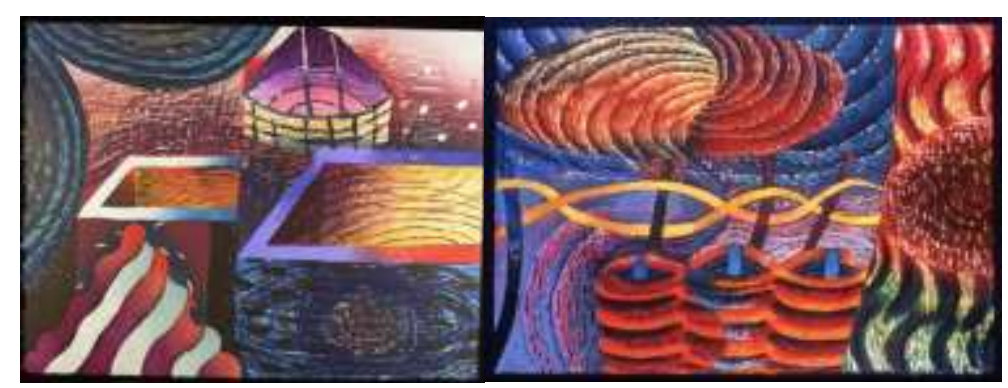

Resim 1 - "Found/Made Mosaic" (Bulunan/Yapılmış Mozaik), Ağaç Baskı, 49x64 cm, 1990.

Resim 2 - "Largely Looming” (Büyük Ölçüde Yaklaşan), Ağaç Baskı, 77 x 107 cm, 1990.

Sanatçının baskıları ilk bakışta tamamen soyut gibi görünse de, şekiller biyomorfik nesneleri veya jeomorfik olayları akla getirir. Largely Looming (1990) (Bkz. Resim 2) ve Garden Pevelations (1989) gibi çalışmalarda yer alan büyük dairesel formlar, girdapları veya volkanik kraterleri düşündürürken, Drama of Source (1990) gibi baskılar arasında dolanan eğrisel şekiller, akan nehirleri akla getiriyor.

Bu çağrışımlar, eserlerin içeriğine dair ipuçları sağlayan Garden Revelations (1989) ve Gems of The Web (1991) (Bkz. Resim 3) gibi başlıklar ile de güçlendirilmiştir. Kunc, bu imgelerin başlangıçta şekil olarak başladığını, ancak son halleriyle bazı objeleri anımsattığını kabul etmektedir. Sanatçı, bu eserlerin soyut değil, ekoloji ve yaşam süreci gibi geniş, evrensel konuları ele aldığını belirtir (Mamiya, 1991).

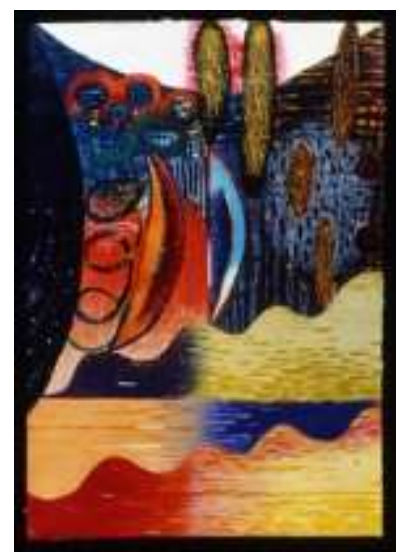

Resim 3 - "Gems of the Web” (Web'in Mücevherleri), Ağaç Baskı, 77x 107 cm, 1991.

5. Uluslararası Prag Grafik Trianeli’nde Kunc'un deneysel baskıları hakkında şöyle denir:

Kunc'un baskıları planını şansa karşı dengeleyen bir sürecin sonucudur; kompozisyonunun geniş ana hatlarını yerleştirir, şu anda ilgisini çeken motifleri minyatürde keşfeden sayısız küçük eskizlerden yola çıkarak geliştirir. Baskı için blokları 
kestikçe, zanaatını, görüntüleri üzerinde çalıştığı malzemelere uyarlamak için kullanır. Kalıbı hazırlarken ahşabın ona rehberlik etmesine izin verir. Aynı şekilde, baskılarının son renkleri, birçok mürekkep katmanının uygulamalarına verdiği tepkinin sonucudur ve işin son paleti, mürekkeplerinin etkileşimlerinin etkileriyle sürekli deney yapma sürecinin bir sonucudur. (Stevens, 2007)

Karen Kunc'un gravürlerinde çokça bulunan belirsizlikler, izleyicinin hem gözünü hem de zihnini meşgul eder. Eserler, sanatçının dikkatli bir şekilde düşünmesinin sonucu olsa da, izleyiciyi görüntüleri keşfetmeye ve bireysel bir sonuca varmaya teşvik etmektedir. Sanatçı eserlerinde izleyiciye çağrışımlar aracılığıyla yönlendirmeler yapar. Kunc'un uyguladığı bu yöntemin zorluğu, heyecan verici ve ilgi çekici yollarla bunları çözme yeteneği, pek tabii baskılarına yansımakta ve bu eserlere benzersiz bir güç ve enerji kazandırmaktadır.

Annesi ve babası kuyumcu olan sanatçı, onların doğadan beslenerek yaptıkları tasarımlar ile çevredeki taş ve fosillerden de faydalanmalarının onun sanatı için en büyük hazine olduğunu ifade eder: "İlk anılarım, çizime olan yatkınlı̆̆ım sebebiyle, hep sanatçı olacă̆ımı bilerek büyüdüm. Kampçıllk, yürüyüş, kano gezileri ve önemli ölçüde seyrek çöllerde ve terk edilmiş taş ocaklarında kaya avı gibi doğal bir çevrede yaşadım. Bu bana dünyanın hazinelerini açığa çıkardı ve görsel duyularımı ve dünyanın nasıl oluştuğuna dair "bilimsel olmayan" anlayışlarımı etkiledi." https://femmesfollesnebraska.tumblr.com)

Gerçekten de sanatçının yaptığı çalışmaların pek çoğunda fosillerden izler, parıltılı taşlar varmış hissine kapılamamak mümkün değildir. "Muhtemelen baskllarımda bulunan dairesel harflerin çoğu, ebeveynlerimin üzerinde çalıştı̆̆ bazı taşları temsil ediyor veya sembolize ediyor." Sözüyle Kunc,bu durumun baskılarına nasıl yansıdığını daha net bir şekilde açıklamaktadır.

Sanatçıyı tüm bu zaman boyunca sadece taşların şekilleri ve renkleri değil, tarih ve kökenleri, yani jeolojileri ve coğrafyaları da büyülemiştir. Karen Kunc'un işinin, varlığının derinliklerinden kendisine fisıldayan çığlıkları modellediği 'yassı mücevher' yatmaktadır. Aynı şekilde eşi Kenny Walton'un gerçekleştirdiği sanatsal cam üretimleri de onun çalışmalarında sürekli bir besin ve ilham kaynağı olmuştur (Hernández, 2015).

Kunc'un eserleri biçimsel bakış açısıyla değerlendirildiğinde, bilinçaltındaki organik ve geometrik formlar, ailesinden gelen bu takı tasarımlarıyla yakından bağlantılıdır. İlk bakışta çok karmaşık etkiye sahip olan bu kompozisyonlar, bu etkiyi kolayca hissettirmektedir. Sanatçı doğadan pek çok kavram ve metafor yakalayarak bunu kendi hayal gücü ve öz bilincine göre resmetmiştir. Çalışmalarında tema olarak, deprem, eriyen karlar, kasırga, yağmur ve kar firtınaları gibi doğa hareketleri görülmektedir (Bkz. Resim 4). Ayrıca insanoğlunun çevre üzerindeki yıkıcı etkisi de seçtiği konular arasındadır. Resimlerinde sık sık kırsal çevrenin yumuşaklığını, kentsel çevrede hüküm süren düşmanlık ile karşıllaştırır. Bunu da, bir yandan ağaçları, vadileri, nehirleri ve denizleri, diğer yandan kirlilik, gazlar, bakteriler ve gezegenin ve hepsinin refahını bozan ve zarar veren zehirli maddeleri temsil ederek somutlaştırmaktadır (Hernández, 2015).

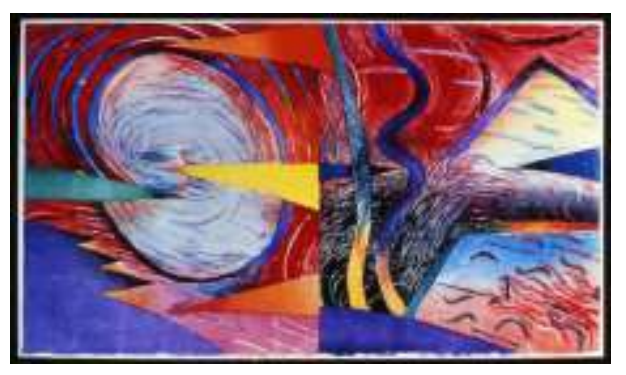

Resim 4 - “Spinning Out the Storm” Ağaç Baskı, 60x104 cm, 1988. 
Çalışmalarına sembolojik açıdan bakıldığında ise, daha çok geometrik formlar öne çıkmaktadır. Bu formlar, birçok atadan kalma kültürde olduğu gibi, fiziksel dünyayı metafizikle bağlayan sembolik unsurlar olarak oluşturulmuştur. Yeni neslin etkisinde olduğu iletişim ve elektronik imgelerin aksine, Karen, ölçü, oran ve nicelikle desteklenen boşluklara ve geometrik şekillere önem vermeye kendini adamıştır (Da Silva, 2005: 1-2).

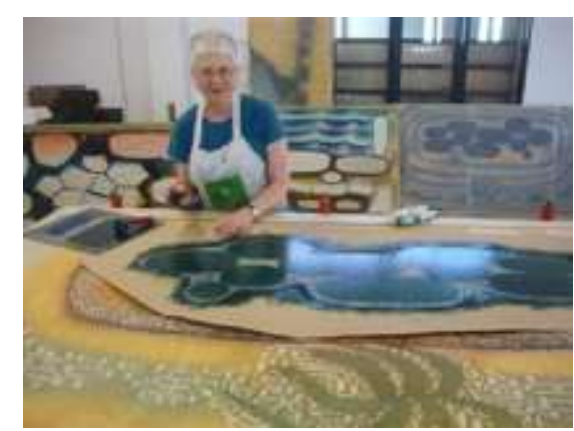

Resim 5 - Karen Kunc, Venedik Baskıresim Stüdyosu'nda büyük ölçekli gravür baskısı yaparken,

Nisan 2011.

Deneysel baskılarıyla tanınan Karen Kunc, 2011 yılında iki ay gibi kısa bir süreliğine Venedik'e gider ve orada yaşamın içinde yer alarak, izlenimlerini baskı yoluyla kayıt altına alır. Sanatçı Venedik'te Su'yla çevrili olmayı deneyimleyerek bilincinin farkındalıkla kaplandığını görür. $\mathrm{Bu}$ deneyim onun için, o zamana kadar doğal ve insani etkilere sahip bir yer ve mekan olarak kabul edilen, kökleri peyzaja ve toprağa dayanan bir insan olarak onda ilginç bir şekilde tezatlık oluşturur ve bu resimde de (Bkz. Resim 6) görüldüğü gibi oldukça büyük ebatlı ahşap plakalarla kalıbını hazırlar.

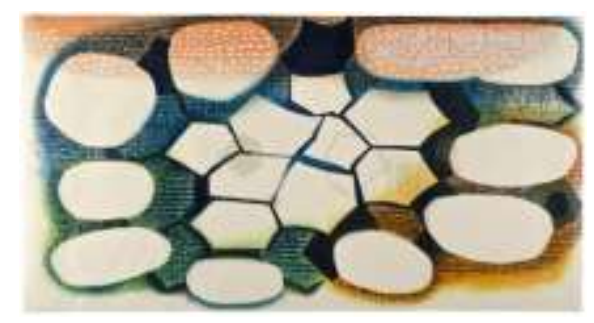

Resim 6 - "Whelming Waters" (Ağlayan Sular), Ağaç Baskı, 100x183 cm, 2001.

$\mathrm{Bu}$ yaşadığı ilginç deneyimi Karen kendi söyleriyle şöyle ifade etmektedir: " $B u$ 'The Immeasurable' (Ölçülemez) serisinde, dayanıklılık ve akıcllk, derinlik ve mesafe, yansıma ve kırılma, rüzgarla savrulan desenler ve dalgalanan su hareketleri hakkında fikirler ve görüntüler yansittyorum. Çalışmam bana, yaşamın ve yenilenmenin, ortak yaşama ait iliş̧kilerin ve düzenin sonsuz döngüsüne dair geniş yaşam meseleleri ve metaforlarından bahsetme ve güçlü imgelerle bir sanatçı-eylemci olarak lirik ve keskin soyutlama yaratma yeteneği veriyor." (https://femmesfollesnebraska.tumblr.com) bu ilginç deneyim karşımıza işte bu eşsiz tasarımları çıkarmaktadır.

Kunc'un çalışmaları bir seri olarak incelendiğinde, bir anlamda Avrupa modernizmini geleneksel Japon baskıresmiyle birleştirmiş olduğu görülmektedir. Hem yirminci yüzyılın başlarındaki Alman Ekspresyonizminin hem de yedinci yüzyıl Japon ukiyo-e baskılarının kalıntılarını sentezleyerek, büyük incelik ve karmaşıklıkla yeni eserler yarattığı açıktır. Metrick L. 
adlı sanat tarihçisine göre, "doğadan soyutlama, sofistike renk oyunu ve bir kompozisyondaki çizgi, pitırtı ve ritmik hareketin karmaşı entegrasyonu ile Japon resmiyle bağlantısı olduğu hissedilir. Aynı anda doğaya gönderme yapan ve esrarengiz şifreleri düşündüren tekrarlanan organik şekiller vardır. Böylelikle eserin kendisi bir kriptograf haline gelir ve diğerlerinin de belirttiği gibi, sonuç, doğal güçleri kopyalamayan, ancak onların süreçlerine benzetme haline gelen bir baskıdır" (Metrick, 2001).

Karen Kunc'un uyguladığı bu deneysel yöntem ve içerik arasında bir uyum vardır. Çalışmaları ve yöntemi arasındaki uyumu şöyle ifade eder; "Birçok fikir, gelişmelevrim düşüncelerinden ortaya çıkar ve küçücük şeyler, görünüşte önemsiz işlerden yola çıkarak, bütün dünyayı değiştirmeye varabilir..." (Grabowski, Fick, 2011:88). Onun renkli ağaç baskıları izleyiciyi yalnızca tefekkürle, herhangi bir zaman kavramını kaybetmeye teşvik etmez, aynı zamanda yaratıcının iç evrenine, mecazi anlatıma da çeker. Yaratımlarına hayranlıkla bakan izleyici, kullanılan farklı şekil ve renklerdeki semboller aracılığıyla, onun ruhunun titreşimlerini hissetmekten kendini alıkoyamaz.

\section{Sanatçının Akordeon Kitapları}

Sanatçının tek sayfadan oluşan baskıresimlerinin yanı sıra çokça baskı yöntemiyle hazırladığı akordeon görünümlü kitap veya kitapçıkları da vardır. Bunlar oldukça etkili kimi küçük ebatlarda kimisi devasa boyutlardadır. Duvarda sergilemenin dışına çıkan bu çalışmalar düz bir yüzeye ayak bastırarak, hatta sayfaları izleyiciler tarafindan rahatlıkla incelenebilsin diye açılmış bir biçimde sergilenmektedir.

Karen Kunc bu akardeon kitaplar hakkında şöyle bir açıklama yapar: "Kitap klasik bir biçimdir. İşlevi kabul edilir, bilinir. Duygusu tanıdıktır. Bu biçimdeki imgelerim bir geçerliliğe, bir 'gerçekliğe' izin verir ve ' Doğruluk, gerçeği görmek gibidir Bu, kitaplardaki bilginin bu kabulü ve onun formuna aşinalığımızla olur... Ancak sanatçılar, basılı sayfayı körü körüne kabul etme eğilimine de işaret ediyorlar ve bu kadar çok kelimenin anlamı nedir? Kelimeler nereden geliyor, onları kim söylüyor ve hangi nedenlerle?... Asıl ses içimizde. " (http://www.vampandtramp.com) Esasen bu yeni bakış açısıyla sanatçı baskı yöntemiyle yeni denemeler gerçekleştirmekte, baskıresme deneysel bir ifade yoluyla yaklaşmaktadır.

Kitap-çıklarında ilginç bazı imgelere değinen Kunc, bu yeni çalışmalarını şöyle betimlemektedir; "Nefes, rüzgar, akintılar, evrimsel büyüme gibi görünmez gerçekliklerin vizyonlarından veya hayallerinden türetilen, icat edilmiş manzaraların ve formların yeni baskılarını yarattım. Renklere, doğal biçimlerin soyutlamalarına, doğal görüntülerin sinırlamalarına ve aşırılıklarına karşı çıkan imgelerle devam eden ilgim, daha önce erişilemeyen manzaralar yaratmayı amaçlıyor - kendileri de bazen insan müdahalesinin neden olduğu garip abartılar olan melez biçimler (dügü̈mler, girdaplar, labirentler, daireler, tümörler, gömülü fideler, filizlenmeler gibi), ancak hayatta kalmak için gerekli. Bu çalı̧̧ma, sürecin ve yüzey fizikselliğinin bir kutlamasıdır" (Kunc, 2008). Kunc bu çalışmalarıyla, kendi dünyasını, gördüklerini, incelediklerini ve içgüdülerini ve yaşamsal sorunlara kadar tanık olduğu olayları yorumlamaktadır.

$\mathrm{Bu}$ akordeon kitapların her sayfasında renkli baskılar mevcutken, yer yer aralarına serpiştirilmiş bazı şairlerin şiirlerinden alıntılar görmek de mümkündür. Çoğunlukla ahşap plakayı oyarak yaptığı bu seriler üzerine çinko plakalara şiirler yazılarak tipo-grafi yoluyla esere eklenmektedir. Bazıları ciltlenen, bazıları ise katlamalardan oluşan kitaplardır. Her birinden farklı sayılarda çoğaltmalar yapan sanatçı diğer eserleri gibi bunları da satışa sunmaktadır. 


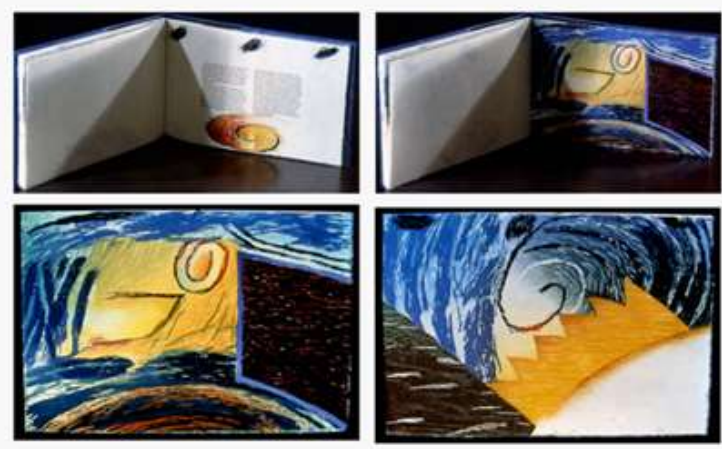

Resim 7 - “Golden Lore”, Ağaç Baskı, 15x23 cm, 12 yaprak, Avoca, Nebraska, 1986-1987.

$\mathrm{Bu}$ çalışma sanatçının ilk hazırladığı kitaplarından birisidir. Burada erken dönem metinlerinin Kunc'un çağdaş sanatıyla birleşmesi görülmektedir. Bu çalışmadaki metinler eski zaman ait kaynaklardan alınmıştır: George Starkey'in 17. yüzyıla ait bir çalışması olan 'The Stone of the Philosophers; Hermes Trismegistus'un Altın Yolu' (dördüncü veya beşinci yüzy1l); ve 1650'den Paracelsus'un (Theophrastus von Hohenheim) "Yazdığı Şeylerin Doğası". Bunların hepsi de altın yapma süreciyle ilgili metinlerdir. "Şimdi, Antik Filozofların Suyu dört maddeye ayırmak için böldügünü anlayacaksınız; 1-2 ve üçe bir; üçte biri renk; bu pıhtılaşma nemidir; ancak diğer üçte ikisi Bilgelerin Ağırlıklarl..." gibi yazılar geçmektedir. Kunc bu eseriyle ilgili şöyle der; "Metin ve tam sayfa ăgaç baskı illüstrasyonlar, yaratma sanatını çevreleyen bir vizyon ve gizem yaratmak için dönüşümlüdür. Doğa, ortaçağ anlayışı ve bu çağdaş imge içinde canlandırılmıştır." (https://abecedariangallery.com). Çocuk kitaplarını anımsatan bu kitapta şiirler için boş alanlar yaratılmış, yaptığı baskılarla bütünleştirmemiş olduğu görülmektedir.

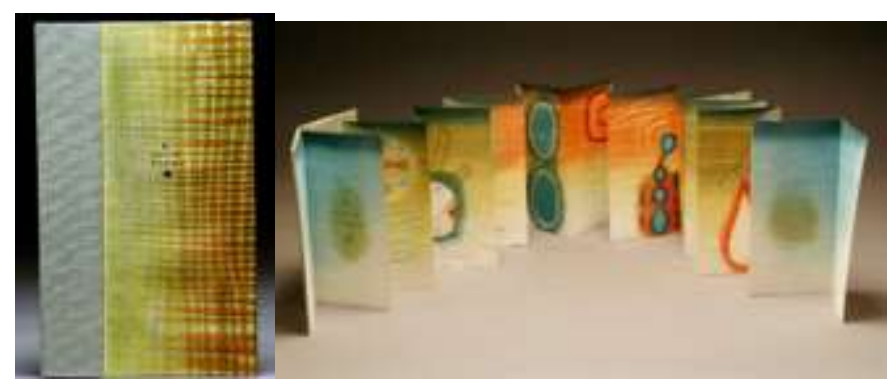

Resim 8 - “Quotes from Hafez” (Hafız'dan Alıntılar), Ağaç Baskı, $5 x 9$ cm, 25 Sayfa, Nebraska, 2006.

Bu kitap-çığın adı 'Hafiz'dan Alıntılar'dır. Bu çalışmada sanatçı kutsamaları ve gücü temsil eden elleri çizilmiştir. Kitap içerisinde Daniel Ladinsky tarafından çevrilen Sufi üstadı Hafız'dan (1320-1389) alıntılanan bazı şiirler vardır. 10 katlamadan oluşan bu kitap-çık bir cilt kapak içerisinde toparlanmıştır. Görüldüğü gibi her yüzeyde birbiriyle uyumlu renkler kullanılmakta ve bu şekilde sayfalar arasında uyum sağlanmaktadır. Diğer dinlere olguğu gibi Sufizme de ilgi duyan sanatçının Hafız'dan şiirler alıntılaması da oldukça ilgi çekicidir. 


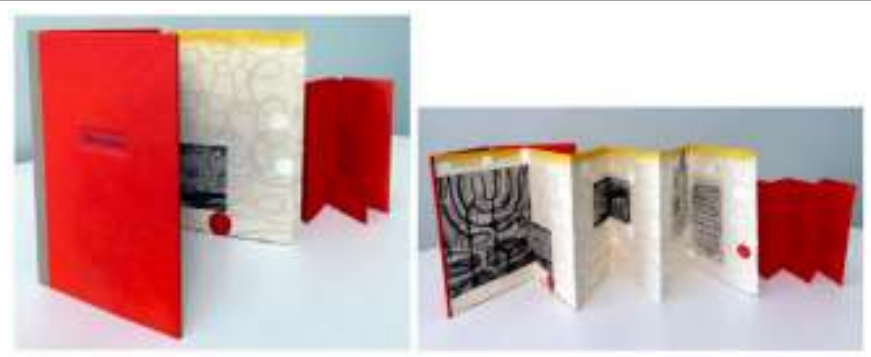

Resim 9 - "Treatsyse”" (Antlaşma), Ağaç Baskı, 23x15 cm, 6 sayfa, Lincoln, Nebraska, 2017.

Akordeon yapıdaki bir diğer kitap 'Antlaşma' adını taşır. Yakın zamanda basılmış olan bu eser, bahçecilikle ilgili tarihsel metinlere atıfta bulunan vinyetleri aşılayıp derleyen, süreç ve teknik bakımından melez bir formdur. Görüntüler, doğal ilerlemelerin ve süslemelerin doğal enerjileri ve ritmik akışıyla grafiksel olarak canlıdır ve 'hayat ağacı, 'ikiz sarmaşıklar, filozofların taşı ve basamaklı çiçek bolluğu yer alır. Metin benzeri girdapların ve filigranlı hafif yazıların' korku boşlukları 'arasında yer alır. Minimal renk geçişleri kitabın yapısını ve akışını vurgular; beyaz noktalar ve daireler gözü harekete geçirir ve dikkat noktaları ve el işaretleri veya notasyonlardan oluşan alternatif bir dil olarak hizmet eder. Tümü, uzmanlık bilgisi ve 'doğal büyü' üzerine aydınlatma toplantılarını akla getirir. Burada kullanılan şiir Karen Kunc'a ait olup, sanatçının bilinçaltının bir yansıması denebilir. Sanatçı bu eseri yaparken İngiliz John Wolfe tarafından 1586'da basılan “Thomas Hill 'A Gardener's Labyrinth"den etkilenmiştir. (http://www.vampandtramp.com)

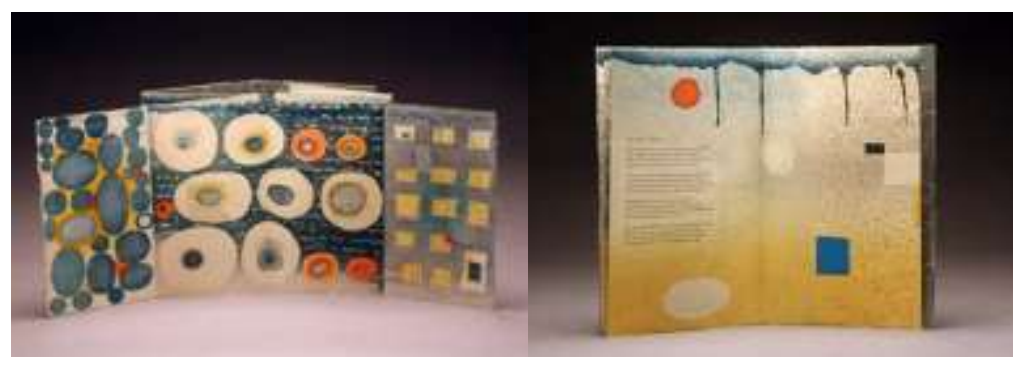

Resim 10 - "Efemera" (Geçici Şey), Ağaç Baskı, $6 x 10$ cm kapalı, 10x42 cm'ye uzanıyor, 12 sayfa,

Avoca, Nebraska, 2009.

Sanatçı 'Geçici Şey' alı bu çalışmasında ödüllü şair Robert Pinsky'nin bazı şiirlerinden esinlenerek bu akerdeon kitabı hazırlamıştır. Eserde Pinsky'nin iki şiiri bulunmaktadır: 'Rhyme' ve 'The Want Bone'. Kunc bu çalışma hakkında şu şekilde bir açıklama yapar: "Kelimelerde ve görüntülerde, mikro-makroskopik dokunaklı anlam ve hafiza katmanları, yakından tutulan ve geçici bir harikadır, tıpkı ışı̆̆ın tek bir ışıklı zarfta recto ve verso basklyı eritmesi gibi. Mahremiyetler, okuma, izleme, meditasyon yapma, dalma eyleminde yakalanır ve kaybolur" (https://abecedariangallery.com). Evrende varolan herşeyin birbiriyle görünmez bir bağ içinde varolduğunu düşünen sanatçı, bu çalışmasıyla da, izleyiciye farkettirmeden bir meditasyon yapmaktadır. 'Efemera' adlı bu eser Kunc'un bilinçaltındaki verileri baskı yoluyla resimlerine katardığı etkili eserlerden biri olarak karşımıza çıkmaktadır. Bu çalışmada sanatçının diğer kitaplarından farklı bir katlama şekli kullandığı görülür. 


\section{Sonuç}

Karen Kunc çağdaş baskı sanatının en üretken ve etkili sanatçılarından biridir. Nebraska'da yaşayan ve çalışan baskı sanatçısı, öncelikle renkli ağaç baskılarıyla tanınır. Eserleri büyük ölçüde Japon ağaç baskılarından ve Alman Ekspresyonistlerin çalışmalarından etkilenmiştir. Eserleri, hava durumu, göç ve erozyon gibi doğa güçlerinden büyüsüne kapılmasından ileri gelir. Eşsiz baskı tarzı, bu kavramları yaratma, koruma ve insan mitine ve metaforuna gönderme gibi ikonik görüntüler içermektedir. Baskıları, ağaç baskının doğasında var olan yıkım ve yaratma sürecini kaydetmekte ve bir sanatçı olarak, evrimsel seçimler ve görüntülerinin çözümüne doğru ilerleyen süreç olarak her şeyi bilen bir rol üstlenmektedir. Ağaç gibi ilkel bir malzemenin sınırlarını zorlayan sanatçı, kendi yaşam deneyimine dayanan sembolik bir ifade yoluyla, başarıya ulaşmayı hedeflemektedir. $\mathrm{Bu}$ nedenle dağ, taş, su, ağaç ve yol gibi imgeler, onun duyusal ve dünyevi dünya arasındaki düşüncelerinin sembolleri haline gelir. Baskılarında ön plana çıkan enerji ve coşku izleyici sarmaktadır. Karen Kunc, deneysel yaklaşımlarıyla izleyiciye özgün baskıda sınırların zorlanarak neler yapılabileceğini kanıtlayan eşsiz eserler üretmiş̧tir. Sanatçının baskıresimlerinde uyguladığı katmanlar, izleyicilere dişavurumculuğu ve yenilikçi baskı tekniklerini inceleme firsatı vererek, baskıresimde deneysellik ile nelerin mümkün olduğunu göstermektedir.

Sanatçı çerçevelenip duvara asılan resimler dışında üç boyutlu ve zemine ayak basan heykelsi çalışmalar da üretir. Bu baskıresimlerin bazıları yatay, bazıları da dikeydir. Ancak çoğu, günlük izleme alışkanlıklarımızın dışındaki ölçülerde oldukça geniş veya dar panoramalar şeklinde yapılmıştır. Bunlar aslında üç boyutlu akordeon gibi kitapçık şeklinde oluşturulmuş tek kompozisyonlardır. $\mathrm{Bu}$ eserler ile Kunc, teknik bakımdan ve sunuş şekliyle özgün baskıda deneysellik ve rastlantısallığın bilincinde olarak ne gibi başarılar getireceğinin birer göstergesidir.

Karen Kunc dünyada çağdaş baskı sanatının en üretken ve etkili sanatçılarından biri olarak tanınmasına karşın yerel kaynaklar da adı pek geçmemektedir. Bu nedenle de, bu çalışma, çoğu yabancı kaynaklar üzerinden çeviriye dayalı olarak makale ve sergi kataloglarından faydalanılarak hazırlanmıştır. Bu çalışmada, Karen Kunc'un psikolojisinin sanat üretimindeki rolü üzerinde durulmuş ve seçilen bazı eserleri hakkında betimsel analizler yapılmıştır. Bu analizlerde; sanatçının imgeler dünyasını deneysellik yoluyla baskı resim tekniğiyle eserlerine nasıl aktardığı incelenmiştir. Ağaç gibi ilkel bir malzemenin sınırlarını nasıl zorladığı, doğal dünyanın güçlerini seyir ve tefekkürden ilham alarak, eserlerinde dağ, taş, su, ağaç ve yol gibi imgeler ile nasıl betimlediği üzerinde durulmuştur. Baskılarında enerji ve coşku ön planda olduğu vurgulanmıştır.

\section{Kaynakça}

Christin J. M., (1991). Assistant Professor of Art History University of Nebraska-Lincoln, Mid american neighbors: alice: anderews and karen kunc, Catalog, University Galleries, Capitol Off-Set Printing Co. of Little Rock on St. (http://www.karenkunc.com/docs/bibliography/1991ChristinMamiya_article2.pdf) (Erişim Tarihi: 03/10/2020, 17:50)

Da Silva, B. (2005). Ef ímero. Circo, 130, (1-2). (http://www.mansilla-tunon.com/circo/epoca6/pdf/2005_130.pdf) (Erişim Tarihi: 18/10/2020, 18:30)

Dorothy, S. (Şubat 10, 2008). Akron Beacon Journal, Printing layers of beauty. www.Ohio.com, Akron Beacon Journal- (http://www.karenkunc.com/docs/bibliography/2008Shinnreview.pdf) (Erişim Tarihi: 17/10/2020, 13:40)

Farber, Janet L. (2007), Karen kunc: sensory source, Bemis Center for Contemporary Art, Omaha, Nebraska, March 2- May 26, 9(8) (http://www.karenkunc.com/docs/bibliography/2007JanetFarberSens) (Erişim Tarihi: 07/10/2020, 16:30) 
Farber, J. (1995). Karen kunc, exh. Cat. (Ornaha: Josly Art Museum).n.p. (http://www.karenkunc.com/info/activity.php) (Erişim Tarihi: 03/10/2020, 18:00)

Grabowski B. \& Fick Bill, (2011). Baskıresim kapsamlı materyaller\&teknik rehberi. (Çev. Eskier Simber A., Tunç Ziya A.), Karakalem Kitabevi Yayınları.

Hernández, P. (2015).Conceptos y simbología en la obra de karen kunc, ESCENA. Revista de las artes, 74(2), págs. 75-88 ISSN 1409-2522, Universidad de Sevilla, (https://revistas.ucr.ac.cr/index.php/escena/article/view/21164/21364) (Erişim Tarihi: 06/10/2020, 14:20)

Kunc, K. (2001). The printmaking workshop continuum at unl, Journal, 9(1) Spring/Summer. (https://arts.unl.edu/art/faculty/karen-kunc) (Erişim Tarihi: 06/10/2020, 14:50)

Kunc, K. (2008). 8 (3), paper works PMB 324, 4951 East Grant Road \# 105, Tucson, Arizona 85712. (www.paperworks.info, Spring) (http://www.karenkunc.com/docs/bibliography/2008MargaretSuchland-article pdf) (Erişim Tarihi: 03/10/2020, 14:00)

Metrick, L. \& Kunc K. (2001). Woodworking process as content, exh. Cat. (Fort Dodge, IA:Blanden Memorial Art Museum).5. (http://www.karenkunc.com/docs/bibliography/2001LenoreMetrick_article.pdf) (Erişim Tarihi: 05/10/2020, $16: 45)$

Price, M. N. , Buckner C. M. \& Steinberg M. (2007). The Abstract Impulse: Fifty Years of Abstraction at the National Academy, 1956-2006, Hudson Hills. (https://www.si.edu/object/siris_sil_902221) (Erişim Tarihi: 04/10/2020, 10:40).

Stevens, A. (2007). Composer, Catalogue Essay, Grapheion, 5th International Triennial of Graphic Art, Prague (http://karen-kunc.com/docs/karen-kunc-resume.pdf) (Erişim Tarihi: 05/10/2020, 16:40)

Stevens, A. (2007). Paper's weight, Exhibition Catalogue, Bemis Center for Contemporary Art, 2007 (http://www.karen-

kunc.com/docs/bibliography/2007AndrewStevens_PapersWeight_article.pdf) (Erişim Tarihi: 07/10/2020, 10:40)

Utter, D. M. (2008). Worlds in transition, karen kunc and darren waterston chase stroms of the spirit, Visual Art, June 18-24, 2008, Cleveland. (http://www.karenkunc.com/docs/bibliography/2008DouglasMaxUtterreview.pdf) (Erişim Tarihi: 06/10/2020, $13: 20)$

http://www.karenkunc.com/docs/publications/2008MemoryoftheFuture.pdf (Erişim Tarihi: 04/10/2020, 15:00)

http://netnebraska.org/article/news/911717/often-forgotten-role-women-artists-nebraskahistory?utm_source=Email\&utm_medium=Email\&utm_campaign=SigStory (Erişim Tarihi: 03/1 $1 / 2020,13: 40$ )

https://centralbookingnyc.com/artists/karen-kunc/(Erişim Tarihi: 04/10/2020, 11:20)

https://abecedariangallery.com(Erişim Tarihi: 04/10/2020, 12:10)

https://femmesfollesnebraska.tumblr.com(Erişim Tarihi: 05/10/2020, 12:10)

https://aobfineart.com/artist/karen-kunc(Erişim Tarihi: 07/10/2020, 14:30)

http://www.atriumgallery.net/karen-kunc(Erişim Tarihi: 06/10/2020, 13:40) 
https://www.davidsongalleries.com/collections/karen-kunc(Erişim Tarihi: 03/11/2020, 09:30)

https://www.galleryshoalcreek.com/artists\#/karen-kunc(Erişim Tarihi: 07/10/2020, 15:00)

https://kiechelart.com/artist/karen-kunc/(Erişim Tarihi: 10/10/2020, 14:20)

https://constellation-studios.net/blog/author/karen-kunc/page/3/(Erişim Tarihi: 11/10/2020, 16:00)

https://grovelandgallery.com/artist/karen-kunc/(Erişim Tarihi: 13/10/2020, 09:00)

https://www.nadatabase.org/2019/03/24/karen-kunc/(Erişim Tarihi: 13/10/2020, 10:00)

http://2017.mokuhanga.org/karen-kunc-picture-this/(Erişim Tarihi: 13/10/2020, 14:50)

http://www.vampandtramp.com/finepress/b/blueheron.html(Erişim Tarihi: 13/10/2020, 14:00)

https://femmesfollesnebraska.tumblr.com/post/15241131712/karen-kunc-artist(24/10/2020, 12:35)

http://www.aprilvollmer.com/site/wp-

content/uploads/2012/09/ArtinPrintVol2MokuhangaInternationalArticle.pdf (Erişim Tarihi: 20/10/2020, 11:00) 